\title{
Thoracic dust exposure is associated with lung function decline in cement production workers
}

\author{
Karl-Christian Nordby ${ }^{1}$, Hilde Notø ${ }^{2}$, Wijnand Eduard ${ }^{2}$, Marit Skogstad ${ }^{1}$, \\ Anne Kristin Fell ${ }^{3}$, Yngvar Thomassen ${ }^{2}$, Øivind Skare ${ }^{1}$, Antonio Bergamaschi, ${ }^{4,5}$, \\ Antonio Pietroiusti ${ }^{4}$, Rolf Abderhalden ${ }^{6}$, Johny Kongerud ${ }^{7,8}$ and Helge Kjuus ${ }^{1}$ \\ Affiliations: ${ }^{1}$ Dept of Occupational Medicine and Epidemiology, National Institute of Occupational Health, Oslo, \\ Norway. ${ }^{2}$ Dept of Chemical and Biological Work Environment, National Institute of Occupational Health, Oslo, \\ Norway. ${ }^{3}$ Dept of Occupational and Environmental Medicine, Telemark Hospital, Skien, Norway. ${ }^{4}$ Dept of \\ Biomedicine and Prevention, University Tor Vergata, Rome, Italy. ${ }^{5}$ Institute of Occupational Medicine, Catholic \\ University of the Holy Heart, Rome, Italy. ${ }^{6}$ Arbeitsmedizin Abderhalden, Thun, Switzerland. ${ }^{7}$ Dept of \\ Respiratory Medicine, Rikshospitalet, Oslo University Hospital, Oslo, Norway. ${ }^{8}$ Faculty of Medicine, University \\ of Oslo, Oslo, Norway.
}

Correspondence: Karl-Christian Nordby, National Institute of Occupational Health, P0 Box 8149 Dep, N0-0033, Oslo, Norway. E-mail: kcndastami.no

ABSTRACT We hypothesised that exposure to workplace aerosols may lead to lung function impairment among cement production workers.

Our study included 4966 workers in 24 cement production plants. Based on 6111 thoracic aerosol samples and information from questionnaires we estimated arithmetic mean exposure levels by plant and job type. Dynamic lung volumes were assessed by repeated spirometry testing during a mean follow-up time of 3.5 years (range $0.7-4.6$ years). The outcomes considered were yearly change of dynamic lung volumes divided by the standing height squared or percentage of predicted values. Statistical modelling was performed using mixed model regression. Individual exposure was classified into quintile levels limited at $0.09,0.89,1.56,2.25,3.36$, and $14.6 \mathrm{mg} \cdot \mathrm{m}^{-3}$, using the lowest quintile as the reference. Employees that worked in administration were included as a second comparison group.

Exposure was associated with a reduction in forced expiratory volume in $1 \mathrm{~s}$ (FEV1), forced expiratory volume in $6 \mathrm{~s}$ and forced vital capacity. For FEV1 \% predicted a yearly excess decline of 0.84 percentage points was found in the highest exposure quintile compared with the lowest.

Exposure at the higher levels found in this study may lead to a decline in dynamic lung volumes. Exposure reduction is therefore warranted.

@ERSpublications

Cement dust exposure at levels comparable to stated workplace exposure limits may lead to obstructive lung changes http://ow.ly/Zl7ny

A press release for this article is available from erj.ersjournals.com

This article has supplementary material available from erj.ersjournals.com

Received: Dec 082015 | Accepted after revision: March 062016 | First published online: April 212016

Support statement: The European Cement Association, CEMBUREAU, Brussels, Belgium provided funding for the study. Funding information for this article has been deposited with FundRef.

Conflict of interest: Disclosures can be found alongside the online version of this article at erj.ersjournals.com

Copyright $\odot$ ERS 2016. ERJ Open articles are open access and distributed under the terms of the Creative Commons Attribution Non-Commercial Licence 4.0. 


\section{Introduction}

Cement is the key ingredient of concrete constructions. The cement production industry employed $\sim 61000$ workers in the European Union in 2011 [1]. Workers in cement plants are exposed to airborne particulate matter (dust) generated from cement and raw materials during the production of cement. Employees in the construction industry are also exposed to cement-containing dust, although in lower concentrations [2].

Clinker is the main component of cement. Clinker is made by heating a fine particulate blend of limestone and clay, and sources of the other necessary constituents calcium, silicon, iron and aluminium, in a kiln to $1450^{\circ} \mathrm{C}$. The clinker is ground with gypsum, forming cement, which has different properties to the raw materials. The cement takes on strong alkaline and irritating properties when mixed with water [3].

Inhalation of dust during cement production has been linked to airway symptoms and obstructive lung changes $[4,5]$, but the lack of good prospective studies has made it difficult to establish exposure-response relationships [5].

To assess exposure we chose to measure the thoracic aerosol fraction, because this fraction was considered to be the most relevant for bronchial effects [6]. The cross-sectional analysis of the baseline examination of lung function and exposure of the participants, enrolled in 2007, indicated that exposure to dust in cement production may lead to reduced dynamic lung volumes [7]. This is in agreement with several earlier cross-sectional studies [8-13], although nonpositive studies have also been published [14-17]. The aim of the present study was to investigate the longitudinal exposure-response relationship between exposure to dust in cement production plants and dynamic lung function during a 4-year follow-up.

\section{Methods}

Employees of 24 cement production plants without former asbestos cement production, which were members of the European Cement Association, were invited to participate. The plants agreeing to participate were located in eight different countries. The study was planned and performed in close cooperation with national coordinators representing the plants in their country. A total of 4966 workers were recruited for the study in $2007(n=4262)$ and $2009(n=704)$. Plant staff collected air samples, measured lung function and completed questionnaires at baseline, and at follow-up in 2009 (3328 workers) and in 2011-2012 (3238 workers) (table 1). The mean individual follow-up time was 3.5 years (range 0.7-4.6 years). Power calculations indicated that a sample size of 2500 was needed to address both main effects and interaction effects with $80 \%$ power to detect a decline of forced expiratory volume in $1 \mathrm{~s}$ $(\mathrm{FEV} 1)$ of $10 \mathrm{~mL}$ per year at $5 \%$ statistical significance.

\section{Exposure}

Aerosol exposure was measured by personal sampling with thoracic cyclones. The air concentration of particulate matter in the thoracic fraction [6] is hereafter called thoracic aerosol exposure. Details of the exposure measurements and of the production process in the participating plants have been published previously [7, 18]. Exposure was estimated by mixed effect models based on 6111 samples covering 165 combinations of job type and plant. Two plants were excluded because it was uncertain whether sampling was done according to protocol. Predictions of arithmetic mean exposure to thoracic aerosol for each combination of job type (except administration), plant, sampling year and season were computed from the corresponding regression coefficients, the between-subject variances, and the plant-specific residual variance of the mixed effect models $[19,20]$. The exposure model and its use for prediction of individual exposure levels during follow-up are further explained in the online supplementary material.

Workers were likewise classified into job types based on questionnaire information obtained at baseline and each follow-up (table 1). Mean exposures during follow-up were predicted for each individual based on the exposure model and time between spirometry measurements, and their resulting arithmetic mean exposure were classified into quintile levels limited at $0.09,0.89,1.56,2.25,3.36$ and $14.6 \mathrm{mg} \cdot \mathrm{m}^{-3}$, and used as levels of exposure in the analysis of lung function. Employees that worked in administration during the entire follow-up served as a second comparison group.

\section{Lung function}

Spirometric measurements were performed according to American Thoracic Society (ATS)/European Respiratory Society (ERS) guidelines [21], with the same Vitalograph 2160 devices (Vitalograph Ltd, Maids Moreton, UK) at baseline and follow-up. Reversibility testing was not performed. Standing height and body weight were measured and recorded at each test occasion. To increase compliance with the protocol a training programme, including written short versions of the protocol and instruction videos, and site visits by the research team to the plants during the start of each measurement campaign was applied. Forced expiratory volume in $1 \mathrm{~s}(\mathrm{FEV} 1)$, forced expiratory volume in $6 \mathrm{~s}$ (FEV6) and forced vital capacity 
TABLE 1 Characteristics of the participants in the longitudinal lung study of cement production workers at inclusion and follow-up, by country

\begin{tabular}{|c|c|c|c|c|c|c|c|c|c|}
\hline & All & Estonia & Greece & Italy & Norway & Spain & Sweden & Switzerland & Turkey \\
\hline \multicolumn{10}{|l|}{ At inclusion } \\
\hline \multicolumn{10}{|l|}{ Worker and plant overview } \\
\hline Plants & 24 & 1 & 1 & 5 & 2 & 2 & 3 & 1 & 9 \\
\hline Employees & 4966 & 181 & 112 & 642 & 288 & 340 & 355 & 110 & 2938 \\
\hline Females & 327 & 87 & 8 & 15 & 46 & 12 & 32 & 2 & 125 \\
\hline Males & 4639 & 94 & 104 & 627 & 242 & 328 & 323 & 108 & 2813 \\
\hline Age at inclusion years & $36.4 \pm 14.3$ & $27.4 \pm 22.7$ & $38.0 \pm 9.1$ & $38.2 \pm 16.7$ & $40.9 \pm 15.9$ & $45.9 \pm 11.0$ & $45.3 \pm 13.4$ & $43.5 \pm 12.5$ & $33.6 \pm 12.1$ \\
\hline \multicolumn{10}{|l|}{ Job type } \\
\hline Administration & 705 & 18 & 21 & 61 & 36 & 41 & 43 & 20 & 465 \\
\hline Production & 1645 & 83 & 40 & 171 & 88 & 138 & 116 & 28 & 981 \\
\hline Cleaning & 105 & 18 & 1 & 49 & 5 & 5 & 5 & 1 & 21 \\
\hline Maintenance & 1316 & 4 & 32 & 169 & 75 & 80 & 103 & 35 & 818 \\
\hline Foreman & 74 & 8 & 1 & 12 & 3 & 11 & 6 & 0 & 33 \\
\hline Laboratory & 284 & 3 & 6 & 52 & 18 & 10 & 10 & 5 & 180 \\
\hline Other & 618 & 15 & 11 & 112 & 10 & 45 & 29 & 5 & 391 \\
\hline Multiple job types & 219 & 32 & 0 & 16 & 53 & 10 & 43 & 16 & 49 \\
\hline \multicolumn{10}{|l|}{ Previous exposure } \\
\hline No & 2536 & 29 & 27 & 316 & 117 & 146 & 64 & 51 & 1786 \\
\hline Yes & 2430 & 152 & 85 & 326 & 171 & 194 & 291 & 59 & 1152 \\
\hline \multicolumn{10}{|l|}{ Smoking } \\
\hline Never smoker \% & 39.8 & 24.9 & 39.3 & 43.0 & 43.4 & 32.0 & 53.8 & 36.4 & 39.0 \\
\hline Former smoker \% & 9.3 & 7.2 & 6.2 & 15.0 & 18.8 & 26.8 & 22.0 & 17.3 & 3.5 \\
\hline Current smoker \% & 19.8 & 35.4 & 25.9 & 15.1 & 16.3 & 15.6 & 7.6 & 20.0 & 22.1 \\
\hline Smoker unspecified \% & 31.1 & 32.5 & 28.6 & 26.9 & 21.5 & 25.6 & 16.6 & 26.3 & 35.4 \\
\hline Cumulative pack-years & $9.3 \pm 13$ & $9.9 \pm 11$ & $15 \pm 20$ & $10 \pm 14$ & $8.0 \pm 11$ & $16 \pm 20$ & $7.6 \pm 12$ & $14 \pm 19$ & $8.1 \pm 11$ \\
\hline \multicolumn{10}{|l|}{ Follow-up } \\
\hline \multicolumn{10}{|l|}{ Lung volume measurements } \\
\hline Three occasions ${ }^{q}$ & 2201 & 58 & 83 & 211 & 143 & 123 & 209 & 59 & 1315 \\
\hline Two occasions & 1338 & 29 & 20 & 231 & 77 & 99 & 70 & 31 & 781 \\
\hline One occasion & 1427 & 97 & 9 & 200 & 68 & 118 & 176 & 20 & 842 \\
\hline Follow-up time years & $3.46 \pm 0.9$ & $3.26 \pm 1.0$ & $3.07 \pm 0.7$ & $3.32 \pm 1.0$ & $3.67 \pm 0.8$ & $3.62 \pm 0.9$ & $3.68 \pm 0.6$ & $3.50 \pm 0.9$ & $3.45 \pm 0.9$ \\
\hline \multicolumn{10}{|l|}{ Smoking during follow-up } \\
\hline Pack-years per year among smokers & $0.6 \pm 0.5$ & $0.54 \pm 0.4$ & $0.92 \pm 0.6$ & $0.68 \pm 0.5$ & $0.47 \pm 0.4$ & $0.68 \pm 0.5$ & $0.53 \pm 0.4$ & $0.75 \pm 0.6$ & $0.61 \pm 0.4$ \\
\hline
\end{tabular}


(FVC) were recorded. Two of the authors (K-C. Nordby and A.K. Fell) classified each obtained spirogram as either valid or not valid according to guidelines, taking into account the repeatability between the two best curves, the end-of-test criterion and the shape of the curve, discarding the test if cough or extraneous inhalation during the procedure was suspected [21]. We applied an end-of-test criterion of $50 \mathrm{~mL} \cdot \mathrm{s}^{-1}$ for FVC. Participants with at least one valid spirometric measurement were included in the analysis. A valid test at one occasion consisted of at least three acceptable exhalation manoeuvres. The technicians performed a daily calibration and leakage test on the spirometers.

\section{Questionnaires}

A questionnaire about job tasks was designed by the research team in close cooperation with the national coordinators. Information on respiratory health was collected using the International Union Against Tuberculosis and Lung Disease questionnaire [22] with additional questions about allergy, asthma and smoking. Questionnaires were translated from English to the local language by each national coordinator. The translation was checked using translation back into English by a second person. Questionnaires were filled out in connection with each spirometry test. Further details have been presented elsewhere [7].

\section{Data analysis}

Longitudinal changes in dynamic lung volumes during follow-up were analysed as outcomes, using FEV1, FEV6 and FVC all divided by standing height squared $\left(\mathrm{h}^{2}\right)$; FEV 1 and FVC as percentage of the European predicted values (European Community for Steel and Coal) [23]; and the FEV1/FVC ratio. The rationale for using the \% predicted values from the European Community for Steel and Coal was to provide standardisation for height, age and sex, and not to compare individual values with European values. For each analysis, individual data points for FEV1, FEV6 and FVC considered not valid according to guidelines [21] were excluded from that analysis.

Exposure-outcome relationships were analysed by mixed effect regression models using person identity as a random intercept and other covariates as fixed effects. Individual follow-up time in exposure groups served as the exposure variable of interest. This variable was represented in the model by an interaction term between exposure category and follow-up time. Non-administration workers were classified into quintiles using estimates of arithmetic mean exposure computed from the exposure model. Administration workers were treated as a separate group. The lowest-exposed quintile served as the reference. Adjustments were made for plant, sex, age at baseline, smoking, self-reported allergy (yes/no), physician-diagnosed asthma (yes/no), using a respirator for most of the day (yes/no), and previous occupational exposure to dust and gases for more than a year (yes/no). Age at baseline was represented by the actual age and two additional variables representing the number of years in excess of 30 years and 50 years of age, respectively. This was done to allow the baseline effect of age to vary with increasing age. Smoking was introduced into the models both as smoking status at baseline (never-smoker, former smoker, or current smoker of $1-9,10-19$ or $\geqslant 20$ cigarettes a day) and as the number of pack-years at baseline and during follow-up. Additional analysis restricted to non-asthmatics and analysis of interaction effects was also performed. Sensitivity analysis was performed to evaluate the influence from the Turkish participants. Outliers defined by standardised residuals exceeding \pm 3.0 were excluded from analysis. Statistical analysis was performed using STATA version 13.1 (STATA Corp, College Station, TX, USA).

The study obtained approval from ethical research committees in Sweden and Norway (permission number: S-06220), covering all countries. All participants signed a written consent form.

\section{Results}

The baseline lung function values of participants who contributed at least one valid measurement of FEV1 are shown in table 2. We identified one plant in which FEV $1 \cdot \mathrm{h}^{-2}$ increased with follow-up time. This was considered to be due to suboptimal exhalation manoeuvres during spirometry at baseline. Hence, the workers in this plant were excluded from the analysis. The annual decline in $\mathrm{FEV} 1 \cdot \mathrm{h}^{-2}$ in the lowest exposed (reference) group was $12.2 \mathrm{~mL} \cdot \mathrm{m}^{-2}$ (95\% CI 9.7-14.6). The longitudinal declines did not increase significantly with age (results not shown).

\section{Associations between thoracic aerosol exposure and lung function decline}

The estimated arithmetic mean thoracic aerosol exposure for the subjects ranged from 0.09 to $14.6 \mathrm{mg} \cdot \mathrm{m}^{-3}$. Increasing exposure levels were consistently associated with longitudinal declines of FEV 1 and FVC \% predicted (table 3). Likewise, increasing exposure levels were consistently associated with declines of FEV1, FEV6 and FVC, all divided by standing height squared $\left(\mathrm{FEV}_{1} \cdot \mathrm{h}^{-2}, \mathrm{FEV}_{6} \cdot \mathrm{h}^{-2}\right.$ and $\mathrm{FVC} \cdot \mathrm{h}^{-2}$ ) (table 4). Significantly higher declines of lung volumes compared with reference were found in the third quintile of exposure (1.56-2.24 $\left.\mathrm{mg} \cdot \mathrm{m}^{-3}\right)$ and at higher levels for FEV1 and FVC \% of predicted, and in the fourth quintile $\left(2.25-3.35 \mathrm{mg} \cdot \mathrm{m}^{-3}\right)$ and at higher levels for $\mathrm{FEV} \mathrm{l} \cdot \mathrm{h}^{-2}, \mathrm{FEV} 6 \cdot \mathrm{h}^{-2}$ and $\mathrm{FVC} \cdot \mathrm{h}^{-2}$. 
TABLE 2 Dynamic lung volumes at baseline among cement production workers

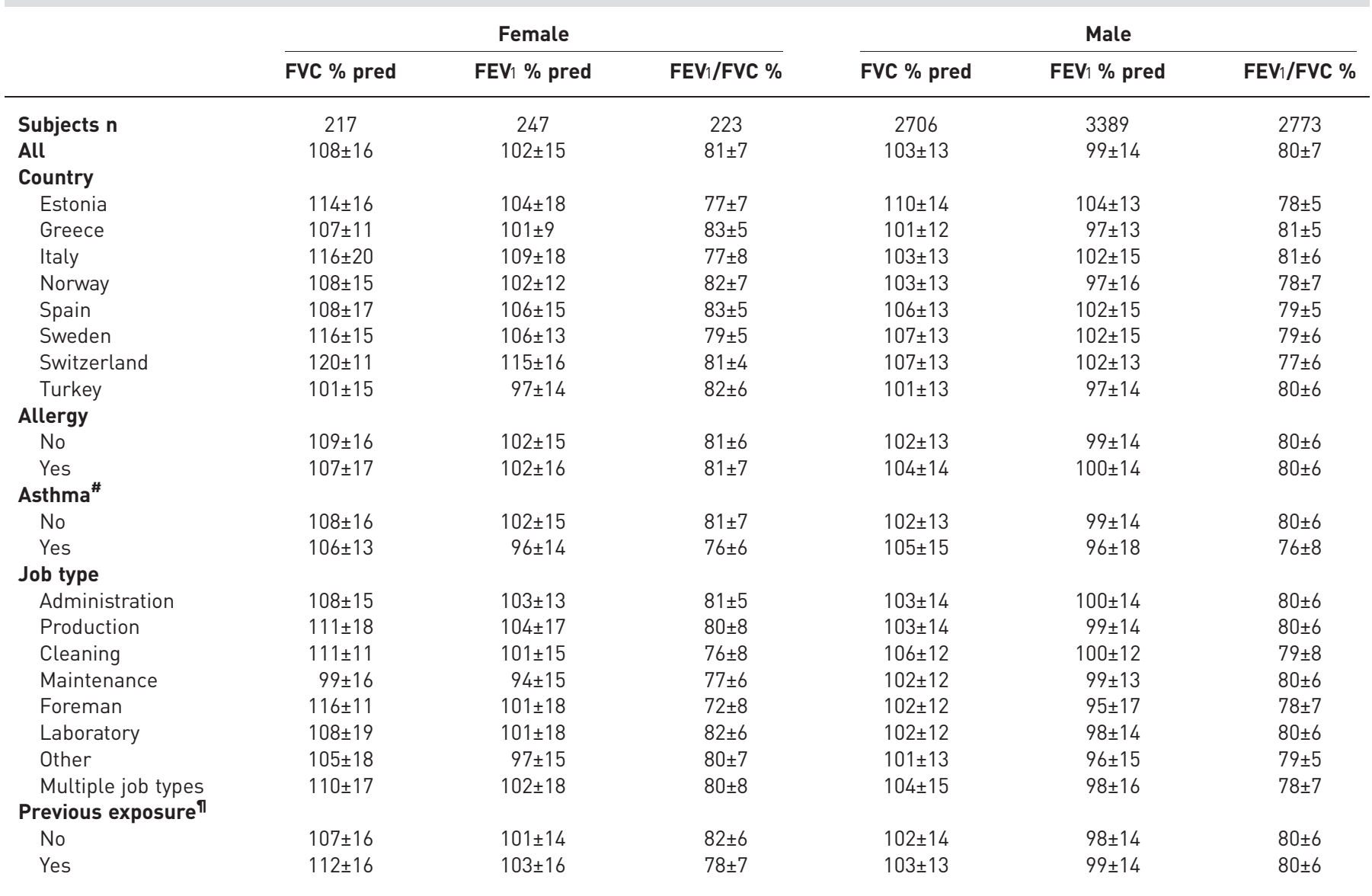

Data are presented as arithmetic mean \pm SD, unless otherwise stated. Individuals with a valid FEV1 measurement at baseline are shown. For measures including FVC, only participants with both a valid FEV1 and FVC were included. Only workers that were included in the final analysis are shown (21 plants were included). FVC: forced vital capacity; FEV1: forced expiratory volume in $1 \mathrm{~s}$. (For FEV1 \% pred and FVC \% pred the values are calculated as percentages of the European predicted values [23].) \#: Asthma was defined as self-report of physician-diagnosed asthma; " : previous occupational exposure to dust or gases for more than a year.

TABLE 3 Associations between cement dust exposure and annual longitudinal change in dynamic lung volume in \% predicted and in \% points of the FEV1/FVC ratio in cement production workers, by exposure category

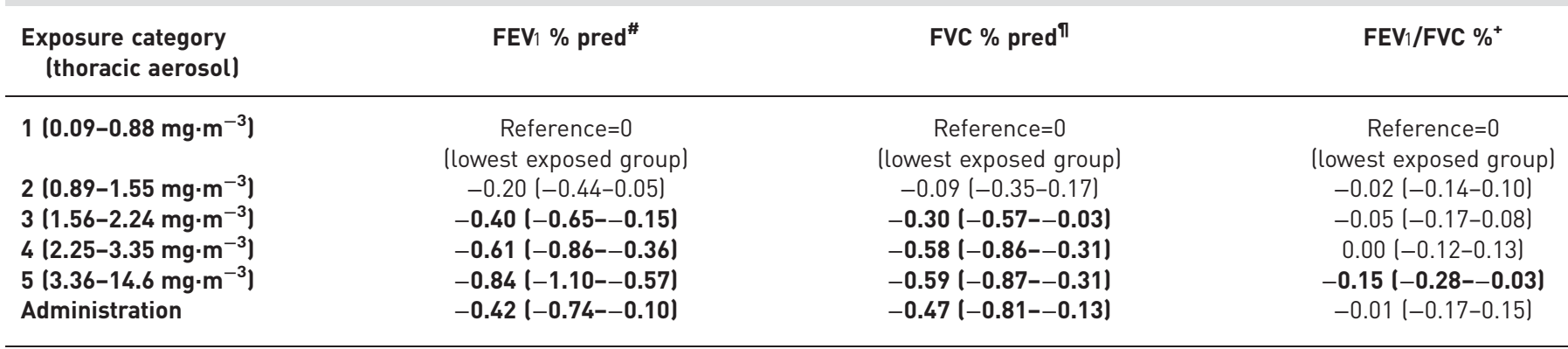

Data are presented as $\%$ points change $(95 \% \mathrm{Cl})$. Estimates are from linear mixed model regression using person identity as a random intercept and other covariates as fixed effects. Adjustments were made for exposure category at baseline (five quintiles plus administration), smoking at baseline $(0,1-9,10-19$ or $\geqslant 20$ cigarettes per day), plant, pack-years of smoking at baseline and during follow-up, allergy (yes/no), physician-diagnosed asthma (yes/no), self-reported use of a respirator most of the time (yes/no), and previous occupational exposure to dust and gases for more than 1 year (yes/no). FEV $1 / F V C$ was additionally adjusted for age at baseline and sex. Bold font indicates estimates that are statistically significant at the $5 \%$ level compared with the lowest quintile from $0.09-0.88 \mathrm{mg} \cdot \mathrm{m}^{-3}$. FEV1: forced expiratory volume in $1 \mathrm{~s} ; \mathrm{FVC}$ : forced vital capacity. (For FEV1 \% pred and FVC \% pred the values are calculated as percentages of the European predicted values [23].) ${ }^{\#}: n=3628 ;{ }^{\text {ๆ }}: n=3377 ;{ }^{+}: n=3399$. 
TABLE 4 Associations between cement dust exposure and annual longitudinal change in dynamic lung volume divided by standing height squared in cement production workers, by exposure category

\begin{tabular}{|c|c|c|c|}
\hline $\begin{array}{l}\text { Exposure category } \\
\text { (thoracic aerosol) }\end{array}$ & $\mathrm{FEV} 1 \cdot \mathrm{h}^{-2 \#}$ & $\mathrm{FEV}_{6} \cdot \mathrm{h}^{-2 \pi}$ & $\mathrm{FVC} \cdot \mathrm{h}^{-2+}$ \\
\hline $1\left(0.09-0.88 \mathrm{mg} \cdot \mathrm{m}^{-3}\right)$ & $\begin{array}{c}\text { Reference }=0 \\
\text { (lowest exposed group) }\end{array}$ & $\begin{array}{c}\text { Reference }=0 \\
\text { (lowest exposed group) }\end{array}$ & $\begin{array}{c}\text { Reference }=0 \\
\text { (lowest exposed group) }\end{array}$ \\
\hline $2\left(0.89-1.55 \mathrm{mg} \cdot \mathrm{m}^{-3}\right)$ & $-1.3(-4.3-1.7)$ & $-1.5(-4.7-1.8)$ & $-1.1(-4.6-2.3)$ \\
\hline $3\left(1.56-2.24 \mathrm{mg} \cdot \mathrm{m}^{-3}\right)$ & $-2.0(-5.1-1.2)$ & $-2.7(-6.2-0.7)$ & $-2.4(-6.0-1.2)$ \\
\hline $4\left(2.25-3.35 \mathrm{mg} \cdot \mathrm{m}^{-3}\right)$ & $-3.8(-7.0--0.7)$ & $-7.9(-11.3--4.4)$ & $-6.3(-9.9--2.7)$ \\
\hline $5\left(3.36-14.6 \mathrm{mg} \cdot \mathrm{m}^{-3}\right)$ & $-7.4(-10.7--4.2)$ & $-8.7(-12.4--4.9)$ & $-6.6(-10.3--2.8)$ \\
\hline Administration & $-4.0(-7.9-0.0)$ & $-7.6(-11.9--3.3)$ & $-7.7(-12.2--3.2)$ \\
\hline
\end{tabular}

Data are presented as $\mathrm{mL}$ change $(95 \% \mathrm{Cl})$. Estimates are from linear mixed model regression using person identity as a random intercept and other covariates as fixed effects. Adjustments were made for exposure category at baseline (five quintile levels plus administration), age at baseline, smoking status at baseline $(0,1-9,10-19$ or $\geqslant 20$ cigarettes per day), sex, plant, pack-years of smoking at baseline and during follow-up, allergy (yes/no), physician-diagnosed asthma (yes/no), self-reported use of a respirator most of the time (yes/no), and previous occupational exposure to dust and gases for more than 1 year (yes/no). Bold font indicates estimates that are statistically significant at the $5 \%$ level compared with the lowest quintile from $0.09-0.88 \mathrm{mg} \cdot \mathrm{m}^{-3}$. FEV $1 \cdot \mathrm{h}^{-2}$ : forced expiratory volume in $1 \mathrm{~s}$ divided by the standing height squared; FEV $6 \cdot \mathrm{h}^{-2}$ : forced expiratory volume in $6 \mathrm{~s}$ divided by the standing height squared; FVC. $\mathrm{h}^{-2}$ : forced vital capacity divided by the standing height squared. ${ }^{\#}: \mathrm{n}=3625 ;{ }^{\text {n }}: \mathrm{n}=3268 ;{ }^{+}: \mathrm{n}=3364$.

Also, employees working in administration had a significantly larger decline of $\mathrm{FEV} 6 \cdot \mathrm{h}^{-2}$ and $\mathrm{FVC} \cdot \mathrm{h}^{-2}$ than the lowest exposed group, but not of $\mathrm{FEV} 1 \cdot \mathrm{h}^{-2}$. For FEV1 /FVC the reduction in the highest exposure level was significantly different from the lowest level (table 3).

\section{Potential confounding and interaction}

To assess the influence of allergy, asthma and using a respirator on the longitudinal lung function changes in the exposed groups, models without these covariates were also built, showing stable estimates of exposure-effect associations with minimal changes of the coefficients. Thus, no substantial confounding from these covariates was present. Also, separate analyses restricted to non-asthmatic individuals were performed. The estimates of exposure-outcome associations did not change substantially from models including and adjusted for individuals with asthma.

In order to assess the interaction between exposure and other factors, models with triple interaction terms including exposure category and potential confounders as indicator variables and time as a continuous variable were applied. Models of interaction between level of exposure and smoking showed additive effects. Likewise, models of interaction between level of exposure and using a mask most of the time showed additive effects, but in the two highest exposure categories, the effect was somewhat, but not significantly, higher among those who did report using a mask than those who did not, with reference to the same exposure quintiles. Further, models of interaction between level of exposure and age above 50 years, previous exposure to dust and gases, and asthma all showed less-than-additive effects, but neither of the interaction terms reached statistical significance.

\section{Sensitivity analysis}

Identical models were run using a reduced dataset excluding Turkey. Omitting all Turkish participants clearly reduced the power to detect significant changes in lung function, with observed widening of confidence intervals. However, we found comparable and stable effect estimates in the four lower exposure categories and in administration, and more unstable estimates in the highest exposure category, regarding models of FEV1 \% predicted, FEV $1 \cdot \mathrm{h}^{-2}$, and $\mathrm{FVC} \cdot \mathrm{h}^{-2}$.

\section{Discussion}

In this study longitudinal declines of dynamic lung volumes among cement production workers were consistently associated with increasing exposure to thoracic aerosol, showing exposure-response relationships. Regarding FEV1 and FVC \% predicted the longitudinal declines were significantly in excess of the reference category for exposures exceeding $1.55 \mathrm{mg} \cdot \mathrm{m}^{-3}$ [23]. This was also the case for $\mathrm{FEV} 1 \cdot \mathrm{h}^{-2}$, $\mathrm{FEV} 6 \cdot \mathrm{h}^{-2}$ and $\mathrm{FVC} \cdot \mathrm{h}^{-2}$ for exposures exceeding $2.25 \mathrm{mg} \cdot \mathrm{m}^{-3}$. For FEV $1 / \mathrm{FVC}$ exposure above $3.36 \mathrm{mg} \cdot \mathrm{m}^{-3}$ was associated with a significantly higher decline than reference. The lung volume declines in the administration group were also higher than reference. The size, the exposure assessment of thoracic aerosol and the longitudinal design make this study unique among studies in this industry. 
Based on the estimated declines of FEV $1 \cdot \mathrm{h}^{-2}$, for a $1.75 \mathrm{~m}$ standing height person (the median of the subjects' height), a $12.2 \mathrm{~mL} \cdot \mathrm{m}^{-2}$ decline in the comparison group and 3.8 and $7.4 \mathrm{~mL} \cdot \mathrm{m}^{-2}$ excess decline in FEV1 in the fourth and fifth exposure quintile, equals a $37 \mathrm{~mL}$ yearly decline in FEV 1 in the comparison group and 12 and $22 \mathrm{~mL}$ excess yearly decline in FEV1 due to exposure, respectively. Over a period of, for example, 20 years, this would lead to an added loss of FEV1 of more than $400 \mathrm{~mL}$ in the highest exposure group, which is considered clinically relevant. Today, no consensus regarding reference values for longitudinal decline in dynamic lung volumes exists [24]. The decline in the comparison group is somewhat greater than reported normal reductions in unexposed nonsmokers (25-30 mL of FEV1) based on cross-sectional data [25].

Only three previous longitudinal studies of cement workers have been identified. In an Italian study including 36 cement workers $53 \%$ were followed for 11 years, showing a decline of $340 \mathrm{~mL}$ in FEV1, equal to an annual decline of $31 \mathrm{~mL}$ [26]. In a study from former Yugoslavia, a 2.4 percentage points decline in FEV1/FVC was reported in an 8-year follow-up of 160 cement workers. The difference between the exposed group and the comparison group of 80 shipbuilders was not statistically significant [27]. In a recent study from Ethiopia a decline in FEV1 and FEV1/FVC of $92 \mathrm{~mL}$ and 1.8 percentage points, respectively, was found during a 1 year follow-up of 45 cement workers, which was significantly greater than the decline among controls [28]. In this study, the exposure was measured as "total dust" and geometric mean exposure levels among production workers were $8.2 \mathrm{mg} \cdot \mathrm{m}^{-3}$, which is a substantially higher exposure level than in the present study.

Also in other industries with exposure to inorganic dust, increased longitudinal declines of FEV1 have been reported [29, 30]. An accelerating decline in lung volumes starting from 20-30 years of age has been indicated from cross-sectional data [25], but this could not be confirmed in the present study.

Declining lung function among workers in cement production plants may possibly be related to airway inflammation. This has been demonstrated both in humans and in animal models after cement dust exposure $[31,32]$. Cement particles possessing irritant effects and components in the raw material, such as organic dust components or crystalline silica, if present, may be factors of importance. However, the levels of respirable crystalline silica have been low in routine measurements performed in cement plants (S. Gardi, Italcimento, Bergamo, Italy; personal communication).

\section{Validity}

In order to obtain valid spirometry measurements manuals in local languages, instruction videos in local languages, training sessions and site visits to the teams collecting the data were performed. Only spirograms considered valid according to ATS/ERS criteria [21] were used for analysis. 5\% of the spirograms were classified as unacceptable regarding $\mathrm{FEV} 1$ and $21 \%$ regarding $\mathrm{FVC}$, using $50 \mathrm{~mL} \cdot \mathrm{s}^{-1}$ as the end-of-test criterion [21]. Since it is known that respiratory disease is a determinant of spirometric failure [33] we chose not to apply the more stringent published end-of-test criterion according to guidelines $\left(\leqslant 25 \mathrm{~mL} \cdot \mathrm{s}^{-1}\right)$. This has been supported by a recent study [34].

Selection mechanisms may possibly have resulted in a healthy worker effect. This has also previously been found regarding FEV1 and industrial exposure [35]. The administration workers showed greater declines in lung function than the reference group for several lung function indices. Several workers employed in administration, such as engineers and health and safety personnel, regularly perform tasks in exposed areas. Administration workers may also undertake less physical activity as part of their work, which may be of importance for their respiratory health [36]. Further, workers in the production departments may be prone to changing their job to administration if they experience adverse airway effects during work, leaving workers who are more resilient to exposure in the exposed groups. Such factors support the choice of low-exposed blue-collar workers as the reference.

Reversibility testing was not performed, since the extra time needed for this procedure was not considered feasible by the plants. To check if estimates could have been biased because of asthma, additional analysis excluding participants reporting asthma was performed. The analysis restricted to non-asthmatics showed similar estimates of effect compared with models based on all participants. Although the covariate representing asthma was significant in a majority of the performed models, asthma did not confound associations between exposure and longitudinal outcomes [37].

The natural longitudinal reduction of dynamic lung volumes may accelerate with increasing age [25]. To account for a possible age effect, we introduced covariates to let the baseline effect vary with age and we also tested for interaction between age $>50$ years (yes/no) and exposure. The estimates of the interaction terms with age were not statistically significant.

Further, analysis of interaction effects of exposure on one side, and smoking, asthma, use of a respirator and previous exposure on the other side were in agreement with additive or less than additive effects. Overall, no significant interaction effects were identified. 
The finding of no protective effect from respirators in this study should not lead to a conclusion that respirators are ineffective, especially since this study did not include any objective assessment of respirator use. Since exposure is measured outside of respirators, exposure-outcome associations will be accordingly underestimated among workers using a respirator. Therefore our results may be generalised to cement production plants where respirators are used with similar frequency as in the current study.

\section{Exposure}

The thoracic aerosol fraction was chosen for exposure assessment. This fraction provides the best estimate for inhaled particles that may deposit in the lower airways $[6,38]$, thus reducing misclassification of the exposure. Such misclassification tends to be nondifferential, leading to a dilution of effect estimates [37]. However, more commonly the respirable, "total dust" or inhalable dust fractions have been used for exposure assessment in occupational studies. In order to facilitate comparisons to other studies, the relationships between thoracic aerosol and other aerosol fractions have been estimated in selected plants participating in the current study [39]. The predicted median ratios of the aerosol fractions in that study were $0.51,2.4$ and 5.9 for respirable/thoracic, total/thoracic and inhalable/thoracic fractions, respectively. If these fractions are multiplied with the lowest exposure level found to be associated with longitudinal lung function decline of $1.56-2.24 \mathrm{mg} \cdot \mathrm{m}^{-3}$ in the current study, the estimated lowest levels of effect found equals $0.8-1.1 \mathrm{mg} \cdot \mathrm{m}^{-3}$ for respirable dust, $3.7-5.4 \mathrm{mg} \cdot \mathrm{m}^{-3}$ for total dust and $9.2-13 \mathrm{mg} \cdot \mathrm{m}^{-3}$ for inhalable dust. For respirable and total dust, these levels are below current occupational exposure limits.

\section{Recommendations and conclusions}

Exposure was associated with longitudinally declining lung volumes at a statistically significant level when exposure exceeded 1.55 and $2.24 \mathrm{mg} \cdot \mathrm{m}^{-3}$ thoracic aerosol, regarding $\mathrm{FEV} 1$ and $\mathrm{FVC} \%$ predicted, and FEV1, FEV6 and FVC, respectively. $40-60 \%$ of the non-administration employees participating in the current study were exposed at or above these levels. Preventive measures beyond respiratory protection should be implemented to reduce exposure as the most important action to prevent lung function decline. The substantial differences between exposure levels in the plants suggest that this should be possible [18].

\section{Acknowledgements}

C. Lorea, I. Claes, A. Tien, S. Gardi and T.R. Thomassen from European Cement Association (CEMBUREAU), Brussels, Belgium launched and organised the setup of this study. M. Grana, L. Coppeta and G. Somma, (University Tor Vergata, Rome, Italy) took part in the scientific design and data collection. S. Sardan (CEIS, Istanbul, Turkey), S. Gardi (Italcementi, Bergamo, Italy), B. Gumauskas (Cementa, Slite, Sweden), M. Martinez Fidalgo and J. Madera (INS, Alcudia, Spain), T.R. Thomassen (Heidelbergcement/Norcem, Brevik, Norway), P. Toom (Kunda Nordic Tsement, Kunda, Estonia), L. Anastasakis (Titan, Thessaloniki, Greece) and A. Streuli (Jura Cement Fabriken, Wildegg, Switzerland) contributed as national coordinators of the study, organising all data collection activities and local adaptations of instruction material and questionnaires. T. Nilsen and O. Synnes at STAMI (National Institute of Occupational Health, Oslo, Norway) provided technical assistance. We also thank the management and employees in the participating cement plants for providing effort and time to carry out the data collection.

\section{References}

1 CEMBUREAU. World Statistical Review 2001-2011. Cement production, Trade, Consumption Data. Brussels, European Cement Association, 2013.

2 Peters S, Thomassen Y, Fechter-Rink E, et al. Personal exposure to inhalable cement dust among construction workers. J Environ Monit 2009; 11: 174-180.

3 Ahmadi H, Durrant CAT, Sarraf KM, et al. Chemical burns: a review. Curr Anaesth Crit Care 2008; 19: 282-286.

4 Bazas T. Review of occupational exposure to dust on the respiratory system of cement workers. J Soc Occup Med 1980; 30: 31-36.

5 Health and Safety Executive. Portland Cement Dust Hazard assessment document EH75/7. Bootle, Health and Safety Executive, 2004.

6 Comité Européen de Normalisation. Workplace Atmospheres-Size Fractions Definition Procedures for Measurement of Airborne Particles (EN 481), Brussels, CEN, 1993.

7 Nordby KC, Fell AK, Notø $\mathrm{H}$, et al. Exposure to thoracic dust, airway symptoms and lung function in cement production workers. Eur Respir J 2011; 38: 1278-1286.

8 Mwaiselage J, Bråtveit $\mathrm{M}$, Moen $\mathrm{B}$, et al. Cement dust exposure and ventilatory function impairment: an exposure-response study. J Occup Environ Med 2004; 46: 658-667.

9 Yang CY, Huang CC, Chiu HF, et al. Effects of occupational dust exposure on the respiratory health of Portland cement workers. J Toxicol Environ Health 1996; 49: 581-588.

10 Noor H, Yap CL, Zolkepli O, et al. Effect of exposure to dust on lung function of cement factory workers. Med J Malaysia 2000; 55: 51-57.

11 Meo SA. Health hazards of cement dust. Saudi Med J 2004; 25: 1153-1159.

12 Al-Neaimi YI, Gomes J, Lloyd OL. Respiratory illnesses and ventilatory function among workers at a cement factory in a rapidly developing country. Occup Med (London) 2001; 51: 367-373.

13 Mwaiselage J, Bråtveit $\mathrm{M}$, Moen BE, et al. Respiratory symptoms and chronic obstructive pulmonary disease among cement factory workers. Scand J Work Environ Health 2005; 31: 316-323.

14 Fell AK, Thomassen TR, Kristensen P, et al. Respiratory symptoms and ventilatory function in workers exposed to portland cement dust. J Occup Environ Med 2003; 45: 1008-1014. 
15 Abrons HL, Petersen MR, Sanderson WT, et al. Symptoms, ventilatory function, and environmental exposures in Portland cement workers. Br J Ind Med 1988; 45: 368-375.

16 Catenacci G, Tringali S, Brunetti G, et al. Decremento di alcuni indici funzionali respiratori in una casistica di esposti a polveri di cemento: studio longitudinale [Decrement of respiratory function indices in a case series of workers exposed to cement dust: a longitudinal study]. G Ital Med Lav 1988; 10: 123-129.

17 AbuDhaise BA, Rabi AZ, al Zwairy MA, et al. Pulmonary manifestations in cement workers in Jordan. Int $J$ Occup Med Environ Health 1997; 10: 417-428.

18 Notø H, Nordby KC, Kjuus H, et al. Exposure to thoracic aerosol in a prospective lung function study of cement production workers. Ann Occup Hyg 2015; 59: 4-24.

19 Rappaport SM, Weaver M, Taylor D, et al. Application of mixed models to assess exposures monitored by construction workers during hot processes. Ann Occup Hyg 1999; 43: 457-469.

20 Seixas NS, Robins TG, Moulton LH. The use of geometric and arithmetic mean exposures in occupational epidemiology. Am J Ind Med 1988; 14: 465-477.

21 Miller MR, Hankinson J, Brusasco V, et al. Standardisation of spirometry. Eur Respir J 2005; 26: 319-338.

22 Torén K, Brisman J, Järvholm B. Asthma and asthma-like symptoms in adults assessed by questionnaires. A literature review. Chest 1993; 104: 600-608.

23 Quanjer PH, Tammeling GJ, Cotes JE, et al. Lung volumes and forced ventilatory flows. Eur Respir J 1993; 6: Suppl. 16, 5-40.

24 Reynolds SJ, Donham KJ, Whitten P, et al. Longitudinal evaluation of dose-response relationships for environmental exposures and pulmonary function in swine production workers. Am J Ind Med 1996; 29: 33-40.

25 Sharma G, Goodwin J. Effect of aging on respiratory system physiology and immunology. Clin Interv Aging 2006; 1: 253-260.

26 Siracusa A, Forcina A, Volpi R, et al. An 11-year longitudinal study of the occupational dust exposure and lung function of polyvinyl chloride, cement and asbestos cement factory workers. Scand J Work Environ Health 1988; 14: $181-188$.

27 Saric M, Kalacic I, Holetic A. Follow-up of ventilatory lung function in a group of cement workers. Br J Ind $\mathrm{Med}$ 1976; 33: 18-24.

28 Zeleke ZK, Moen BE, Bratveit M. Lung function reduction and chronic respiratory symptoms among workers in the cement industry: a follow up study. BMC Pulm Med 2011; 11: 50.

29 Johnsen HL, Hetland SM, Benth JS, et al. Dust exposure assessed by a job exposure matrix is associated with increased annual decline in FEV1: a 5-year prospective study of employees in Norwegian smelters. Am J Respir Crit Care Med 2010; 181: 1234-1240.

30 Ulvestad B, Bakke B, Eduard W, et al. Cumulative exposure to dust causes accelerated decline in lung function in tunnel workers. Occup Environ Med 2001; 58: 663-669.

31 Fell AK, Sikkeland LI, Svendsen MV, et al. Airway inflammation in cement production workers. Occup Environ Med 2010; 67: 395-400.

32 van Berlo D, Haberzettl P, Gerloff $\mathrm{K}$, et al. Investigation of the cytotoxic and proinflammatory effects of cement dusts in rat alveolar macrophages. Chem Res Toxicol 2009; 22: 1548-1558.

33 Becklake MR. Epidemiology of spirometric test failure. Br J Ind Med 1990; 47: 73-74.

34 Hankinson JL, Eschenbacher B, Townsend M, et al. Use of forced vital capacity and forced expiratory volume in 1 second quality criteria for determining a valid test. Eur Respir J 2015; 45: 1283-1292.

35 Eisen EA, Wegman DH, Louis TA, et al. Healthy worker effect in a longitudinal study of one-second forced expiratory volume (FEV1) and chronic exposure to granite dust. Int J Epidemiol 1995; 24: 1154-1161.

36 Watz H, Pitta F, Rochester CL, et al. An official European Respiratory Society statement on physical activity in COPD. Eur Respir J 2014; 44: 1521-1537.

37 Rothman KJ, Greenland S, Lash TL. Validity in epidemiologic studies. In: Rothman KJ, Greenland S, Lash TL, eds. Modern Epidemiology. 3rd Edn. Philadelphia, Lippincott Williams \& Wilson, 2008; pp. 128-147.

38 Vincent JH. Framework for aerosol sampling in working, living and ambient environments. In: Aerosol Sampling: Science, Standards, Instrumentation and Applications. Chichester, John Wiley \& Sons Ltd, 2007; pp. 221-307.

39 Notø HP, Nordby KC, Eduard W. Relationships between personal measurements of "total" dust, respirable, thoracic, and inhalable aerosol fractions in the cement production industry. Ann Occup Hyg 2016; 60: 453-466. 